\title{
Sociocultural Commitment of Cognitive Linguistics via dimensions of context
}

\author{
Nikolay N. Boldyrev \\ Tambov State University \\ Tambov, RU \\ Olga G. Dubrovskaya* \\ Tyumen State University \\ Tyumen, RU
}

\begin{abstract}
The paper explores basic properties of language that can be explained by appealing to its main functions, namely, cognitive, communicative, and interpretive. Although the first two functions have always been recognized, it is only recently that the third one has been outlined (see Boldyrev, 2011, 2012, 2013, 2014). Boldyrev claims that linguistic interpretation reveals static and dynamic processes of cognition shaping overall collective and individual knowledge of language speakers. Viewed from this perspective, linguistic interpretation involves selection, classification, and evaluation within contexts of knowledge that language speakers acquire as members of societies and cultures. These contexts are dependent on metaconcepts -Roles, Stereotypes, Values, Norms, Space, Time, Language Performance - that regulate language use. This paper examines static vs. dynamic, collective vs. individual and the metaconceptual dimensions of contexts of knowledge to suggest that they underlie the Sociocultural Commitment of Cognitive Linguistics.
\end{abstract}

Keywords: Static vs. Dynamic; Collective vs. Individual; Metaconceptual Dimensions of Contexts; CognitiveDiscursive Interpretant

\section{Introduction}

The interdisciplinary approach to Cognitive Linguistics has been characterized as the Cognitive Commitment (Lakoff, 1990) and the Generalization Commitment (Evans, 2012). They represent an assumption on language that accords with what is known about the mind and brain from various disciplines, thus, outlining basic peculiarities of Cognitive Linguistics nowadays: a usage-based view of language; interrelation of cognitive abilities, such as memory, perception, categorization, abstraction and the ability to speak languages; a view on meaning that encompasses both dictionary and encyclopaedic information. However, a fundamental theoretical framework on language cannot be fully integrated without the social perspective as a commitment providing an account of language, language use, and discourse construction that are entirely dependent on the speaker(s) and their knowledge of the world that, in turn, is deeply grounded in cultural and social patterns of behavior acquired by man as a member of a group. This Commitment we claim to be Sociocultural for it is based on the assumption that linguistic abilities

\footnotetext{
“ Nikolay N. Boldyrev is Honoured Scholar of Russian Federation, Professor and Director of the Center for Cognitive Linguistics at Tambov State University named after G.R. Derzhavin, where he conducts research, teaching, and outreach work. Nikolay Boldyrev has worked at analyzing and elaborating the Theory of Linguistic Anthropocentricity on a holistic methodological basis. He currently coordinates 'The Russian Cognitive Linguists Association' and is Editor-in-Chief of Issues of Cognitive Linguistics. E-mail: boldyrev@tsu.tmb.ru

${ }^{* *}$ Olga G. Dubrovskaya is Assistant Professor at Tyumen State University. Her research interests include cognitive linguistics, discourse analysis and intercultural
} communication. E-mail: o_dubrovskaya@inbox.ru 
and language use being deeply rooted in our general cognitive abilities are socio- and culture-specific and represent our knowledge-dependent interpretation of the world we live in as members of micro- (society) and macro- (culture) groups. In this article, Sociocultural Commitment of Cognitive Linguistics is revealed through Context Dimensions that fully demonstrate how meaning is created by speakers of different cultural backgrounds within their contexts of knowledge that predetermine their language use and discourse construction.

The rationale of this work is reinforced by the fact that human cognition is inherently sociocultural and, as Dabrowska and Divjak argue in their 2015 study, "fully integrating the cognitive and social perspective is probably the greatest challenge facing cognitive linguistics today" (Dabrowska \& Divjak, 2015, p. 6). In this article, we present the results of the research project that has been carried out in the framework of Tambov School for Cognitive Linguistics (Russia) that focuses on elaborating a universal theory - the Theory of Linguistic Anthropocentricity - that reveals the anthropocentric nature of language on a holistic framework of cognitive paradigm. Following its basic assumption, linguistic activity involves interpretation as well as conceptualization and categorization and is performed in contexts of knowledge that process and store experience human beings gain during their lives (see, for example, Boldyrev, 2012).

\section{Aim and research objectives}

The aim of the present work is to illustrate the Sociocultural Commitment of Cognitive Linguistics from the viewpoint of contextual dimensions (dimensions of contexts) as inherent characteristics of conceptualization and categorization. The aim is emphasized by the following objectives:

- to exemplify static vs. dynamic dimension of contexts of knowledge;

- to exemplify collective vs. individual dimension of contexts of knowledge;
- to exemplify metaconceptual dimension of contexts in the process of language use.

\section{Method of study}

To implement the research the cognitive-discursive interpretant method of analysis was used (see Boldyrev and Dubrovskaya, 2015). It is rested mainly on the methodologies that are standard in the field of linguistics and cognitive linguistics, in particular. They are empirical, focusing on the meanings and structures of linguistic forms, and are not limited to: the analysis of interaction of thought, language, and body; the examination of linguistic interpretation via corpusbased discourse analysis; the experimental techniques of psycholinguistics; the simulation of human linguistic activity in the field of artificial intelligence.

As a research tool, cognitive-discursive interpretant (CDI) is a technique that has served as the basis for interpreting the world and construing it in discourse. It has the critical task of exposing the mechanisms that underlie interpretation in discourse. Cognitivediscursive interpretant as a process of interpretation and discourse construction involves selection, classification, and evaluation that refer to particular concepts within particular contexts of sociocultural knowledge (Boldyrev, 2012). While selection provides profiling, classification triggers the assignment of the profiled meaning to groups within a system of categorization, and evaluation implies assessment within a set of norms, values, and other standards that a participant acquired as a member of a particular socioculture. As a cognitive structure, cognitive-discursive interpretant narrows interpretation in terms of a particular choice (selection), classification, and evaluation within a particular framework of sociocultural experience and knowledge (see Boldyrev and Dubrovskaya, 2015). The method for cognitive-discursive interpretant analysis underpins the analysis of the corresponding context of knowledge that language speakers activate during the process of language use. 


\section{Reference review}

Basically, the topic of context has been widely researched over the last few decades. It has been covered in a variety of fields, linguistics included. The theory of context in the framework of linguistics has been given special prominence by Boldyrev $(2012,2014)$, van Dijk (2009), Dilley (1999), Kolshanskiy (1995), and others. The researchers aim to show that interpretation and language use as well as discourse construction are dependent upon context that is viewed as "the act of bringing together parts of language into meaningful utterances"; "conditions under which meaning is attributed to a stretch of language"; or still "the environing and surrounding conditions of a specified object" (Dilley, 1999, pp. 4-5). From these perspectives, the notion of context is often claimed to be "vague and ambiguous" (van Dijk, 2009, p. 7) and grounded in the categories of social situations as analyzed in the 1970s-1980s as follows:

- Setting (Scene) that includes place, time, and physical characteristics of the situation;

- Social factors, such as social roles, skills and motivations of participants;

- Social norms and activities that participants observe and perform;

- Cognitive and psychological parameters that encompass goals, knowledge, attitudes and other similar capabilities of participants (van Dijk, 2009, pp. 38-39).

The development of these assumptions has involved research in four main areas: anthropology (e.g., Hall, 1976), sociology and sociolinguistics (e.g., Malinowski, 1989), linguistics (e.g., Halliday, 2003), and cognitive linguistics (e.g., Demyankov, 2005; Kubryakova, 2004). In the framework of anthropology, context is viewed as surrounding circumstances that influence the outcome of communication (Hall, 1976); sociology studies a link between social factors and the way human beings speak
(Malinowski, 1989); the term "context of situation" was elaborated by M.A.K. Halliday who argued that the selection of linguistic form for an utterance is partially determined by features of extra-linguistic context (Halliday, 2003).

However, it is the cognitive perspective to context that has dramatically influenced the social and linguistic approaches re-defining the nature of context. Within the framework of cognitive linguistics, contexts are viewed as mental models (van Dijk, 2009), domains (Langacker, 1987, 2000), and recently as knowledge structures - conceptual-and-thematic domains, such as HUMAN BEINGS, ARTEFACTS, NATURE, WILDLIFE, SPACE, TIME that reflect overall knowledge of the activities each individual is involved in as their everyday experience (Boldyrev, 2011).

We believe that societies as well as cultures set patterns for behavior and human beings make networks of meanings that regulate their lives. It means that Sociocultural Commitment is a commitment to providing a characterization of language that represents sociocultural knowledge of language speakers. We postulate a number of assumptions that underlie the Sociocultural Commitment. First, sociocultural knowledge that humans acquire during the process of socialization as representatives of societies and cultures forms a variety of contexts: contexts of professional knowledge, contexts of knowledge about politics, economics, history, etc. Second, contexts of knowledge being deeply rooted in short-term memory and longterm memory represent static and dynamic processes of conceptualization and categorization and are claimed to be collective and individual. Contexts of collective knowledge feature "dictionary" knowledge that is shared by a particular language group. Contexts of individual knowledge feature "encyclopaedic" information that is not necessarily shared by a language group. They reflect personal modification of the overall knowledge that is acquired by each representative of a sociocultural group and is expressed via language when speakers construct meanings to communicate their ideas. Third, language use as well as discourse construction depend upon metaconcepts - universal knowledge structures all human beings possess irrespective of their nationality, 
ethnicity, language group, or any other group division. We claim that there are the following metaconcepts that structure verbalized cognition: Roles, Stereotypes, Values, Norms, Space, Time, Language Performance.

The metaconcepts ("meta" from Greek, with the meanings "along with", "among", "beyond", i.e. "beyond" concepts) are acquired by each individual throughout their life among groups of people: human beings occupy several roles and get to know how to play them (e.g., that of a child, parent, student, and laborer); human beings assign qualities to groups of people and to themselves creating stereotypes; human beings follow (or ignore) guidelines for action which they consider right or wrong that result in values; they set patterns of behavior acceptable or proper for their community as a system of norms; they structure their experience throughout space and time; they acquire and master language to adapt themselves to the environment in order to satisfy their needs.

\section{Results of study}

Static vs. dynamic dimension of context. Within the conceptual-and-thematic domains Human Beings, Artefacts, Nature, Wildlife, Space, Time that store contexts of knowledge, human beings conceptualize and interpret the world. Statically, the conceptualand-thematic domains represent overall knowledge that participants acquire as representatives of different sociocultural backgrounds in terms of behavior (verbal and non-verbal) typical of some groups. For example, within the HUMAN BEINGS domain there may be a subcategory (subdomain) reflecting men-women relationship as it is seen in the following sample (1):

(Prime Minister): Have you any friends in Bangkok / Sir? //

(Anna): No / I know no one here //

(Prime Minister): Sir is married? //

(Anna): Can you / please / explain to me why you call me sir? //

(Prime Minister): Women do not stand in the presence of His Excellency // ("Anna and the King", a drama film).
There is a huge amount of knowledge that is socioculturally salient and is stored in memory due to the fact that the participants socialize in different backgrounds: Anna in Great Britain and Prime Minister in Siam.

Dynamically, contexts as knowledge structures activate participants' meanings as the result of the interpretive process of selection, classification, and evaluation that constitutes the cognitive-discursive interpretant that, in turn, reflects the dynamic dimension of contexts as knowledge structures. Consider, for example, selection as a choice of conversational topic "Drunkenness" in (2):

(2) LIZA. <..> Besides, he'd poured so much down his throat that he knew the good of it $\langle\ldots\rangle$. Drank! My word! Something chronic <..>. But then he did not keep it up regular [Cheerfully]. On the burst, as you might say, from time to time. And always more agreeable when he had a drop in. When he was out of work, my mother used to give him fourpence and tell him to go out and not come back until he'd drunk himself cheerful and loving-like. There's lots of women has to make their husbands drunk to make them fit to live with $<\ldots>$. If a man has a bit of a conscience, it always takes him when he's sober; and then it makes him low-spirited. A drop of booze just takes that off and makes him happy (Shaw, 1994, p. 98).

Depending on her experience as a child, Liza activates the context of sociocultural knowledge within the conceptual-and-thematic domain BAD HABIT that represents the static dimension of context and a particular meaning "my father was always drunk", which is dynamic. The CDI is represented by the following lexical concepts [POUR MUCH], [DRUNK] that give access to sociocultural knowledge that reveals Liza's background and experience.

In the next sample (3), the participants select different conceptual-and-thematic domains and that leads to a case of misunderstanding:

(3) Man: Does your dog bite?

Woman: No. (The man reaches down to the pet dog. The dog bites the man's hand). 
Man: Ouch! Hey! You said your dog doesn't bite.

Woman: He doesn't. But that is not my dog (data from

Yule, 1997, p. 36).

The CDI as represented by the pronouns your, my activates the context of sociocultural knowledge within the conceptual-and-thematic domain of POSSESION ( $m y$, your dog) and domain of MUTUAL TERRITORY (a pet aside a man is thought to belong to him).

Classification as a cognitive process of interpretation involves categorizations of objects, participants, events, etc. within contexts of sociocultural knowledge that participants activate, as in the next sample (4):

(4). MRS. PEARCE. How can you be such a foolish ignorant girl as to think you could afford to pay Mr. Higgins? (Shaw, 1994, p. 65).

The CDI is represented by the lexical concepts [FOOLISH], [IGNORANT], on the one hand, and the proper name - MR HIGGINS - which represents the idea of belonging to a group of high-status men.

In the next two samples (5-6), education is categorized as a special benevolence of a father to his children (5) and as an imposition of a penalty for a child (6):

(5) THE KING: I desire you all / when of appropriate age / to be educated in English language / science / and literature // This is a necessary and practical gift I give to you ("Anna and the King", a drama film);

(6) THE KING'S SON: Why do you punish me with imperialistic schoolteacher? ("Anna and the King", a drama film).

The CDI of evaluation within contexts of sociocultural knowledge represents a variety of meanings on a broad scale of assessment valuation standards. In the next sample (7), within the context of knowledge about professional and social duties, the speaker activates meaning "not to keep one's word is bad":

(7) ANNA: A monarch who fails to keep his word is uncivilized, unenlightened and ungrateful ("Anna and the King", a drama film).
Within the context of knowledge about menwomen relationships, the meaning that is activated by the speaker (the King's son) in (8) represents the norms that are relevant in a particular country (Siam, for example):

(8) THE KING'S SON: In my country / man never tell / woman he is sorry about anything / ever // ("Anna and the King", a drama film).

The examples illustrate that statically contexts of knowledge serve as scopes of predication, in Langacker's terms (2000), that provide a profile and a base, where the profile designates a conceptual structure within a larger unit, the base. Dynamically, they hold a variety of meanings participants make in the process of discourse construction that reflect their individual knowledge. In discourse, lexical concepts provide access to it relating to particular activities and spheres of life, i.e. representing the knowledge participants acquired as members of a group. The static vs. dynamic dimension of context reveals dictionary and encyclopaedic knowledge of language speakers as it is described under the heading collective $v s$. individual dimension of context.

Collective vs. individual dimension of context. We believe that collective knowledge, i.e. conventionally assumed knowledge, encompasses the overall knowledge that is shared by a particular group distinguishing it from other members of the same or different language group. For psychiatrists, for example, it is common psychiatric practice to employ a mental status examination that allows the clinician to make an accurate diagnosis for coherent treatment planning. The practice to participate in a clinical assessment process irrespective of the time, place, etc. is activated in the next sample (9) with the second psychiatrist suspicious of the mental disorder of the first:

(9) Two psychiatrists walked passed each other in the corridor. "Morning", said one, and nodded. "I wonder what he meant by that", worried the other (Findlater, 2007, p. 340). 
We acknowledge that individuals belonging to the same language group carry collective representations of their environment. Regarding the next example, for any speaker of English the word hold is associated with the idea of "keeping or supporting something or somebody with hands or arms or another part of the body" (Gadsby, 1998, p. 633). It is the very context of collective knowledge that the child activates in the next sample (10):

(10) Teacher: May Tom hold your hand, Lenny?

Lenny (child): No, it is not that heavy (Findlater, 2007, p. 155).

The ability to produce and comprehend metaphorical language is constrained primarily by limitations in children's knowledge and information processing abilities. The teacher, in turn, activates the context of collective knowledge that is represented by the language unit hold somebody's hand which is associated with the idea of "touching and remaining unchanged", "not carrying or taking somewhere" (Gadsby, 1998, p. 633).

In speech, within different conceptual-andthematic domains language speakers activate contexts of knowledge due to such variables as gender, age, profession, territory, religious and / or political beliefs, etc. transforming (rendering) contexts of collective knowledge into contexts of individual, i.e. sociocultural knowledge. For example:

(11) A doctor began his examination of an elderly man by asking him what brought him to the hospital. The old man looked surprised, and said, "Why, it was an ambulance" (Findlater, 2007, p. 80).

In the above sample (11), the doctor activates her/his context of professional knowledge within the conceptual-and-thematic domain ILLNESS, whereas the elderly man - his context of sociocultural knowledge as a patient: within the conceptual-andthematic domain VEHICLE.

The same interplay of contexts of collective and contexts of individual, i.e. sociocultural knowledge is evident in many other examples:
(12) Teacher: What do letters B.C. mean?

Pupil: Before Calculators (Findlater, 2007, p. 35).

The teacher in (12) activates the context of collective knowledge represented by the abbreviation B.C. "Before Christ" within the conceptual-and-thematic domains BIBLE, HISTORY. The student as a representative of IT generation interprets the modern world within the conceptual-and-thematic domains IT, COMPUTERS;

(13) Jonny: Have you seen the new Brad Pitt flick? Jenny: I enjoyed it a lot. Did you like it? (a conversation at a party).

Jonny in (13) indicates group membership distinguishing his identity from the standard speakers of English, activating a context of knowledge within conceptual-and-thematic domain UNOFFICIAL COMMUNICATION by the lexical concept [FLICK].

In anecdotes and funny stories the interplay of contexts is extensively exemplified:

(14) "Did you take the patient's temperature, nurse?"

"No, doctor. Is it missing?" (Findlater, 2007, p. 230).

The doctor in (14) activates her/his professional knowledge as a result of her / his professional duties: treating patients involves taking their temperature, which implies measuring the heat of the body. For the nurse, the context of collective knowledge that represents her / his identity as a general speaker of English becomes relevant: to take means "to move something from one place to another" (Gadsby, 1998, p. 1374);

(15) This bloke has just finished his painless fiveminute check-up at the dentist's. "It must be a real bugger spending all day with your hands in people's mouths,' he said. The dentist grinned. 'I think of it as spending all day with my hands in their wallets. That'll be 25 pounds, please" (Findlater, 2007, p. 231).

The doctor in (15) identifies himself / herself within the conceptual-and-thematic domain 
GETTING MONEY rather than that of PERFORMING PROFESSIONAL DUTIES, no matter how unpleasant they can be;

(16) "Doctor, my hair keeps falling out. What can you give me to keep it in?". "Will a shoebox do?" (Findlater, 2007, p. 231).

The patient in (16) expects the context of professional knowledge from the doctor; the doctor, however, activates the collective knowledge represented by the word keep ("to continue to be in a particular place or condition" (Gadsby, 1998, p. 717)) within the conceptual-and thematic domain CONTAINER;

(17) "Doctor, what should I do if my temperature goes up by more than a point?" "Sell! Sell!" (Findlater, 2007, p. 231).

Discourse in this example (17) is constructed within the conceptual-and-thematic domain SYMPTOMS OF ILLNESS on the one hand, and that of MARKET, on the other. By activating different conceptual-and-thematic domains, the speakers represent their sociocultural knowledge they acquire throughout life.

The interplay of conventionally assumed knowledge and individual knowledge is instantiated by universal structures - metaconcepts that are described next.

The metaconceptual dimension of contexts. The metaconcepts Roles, Stereotypes, Values, Norms, Space, Time, Language Performance serve as 'filters' through which the static dimension of contexts of knowledge becomes dynamic; collective - transforms into individual. The metaconcepts are claimed to be mental structures that reflect overall knowledge human beings posses, process, and acquire. Irrespective of the country in which human beings live, the territory they occupy, languages they speak, or space and time boundaries, they learn values and norms, adopt stereotypes, agree or disagree about them, and construct discourse profiling the type of context they believe or feel relevant to the communicative situation. In speech, the metaconcepts are instantiated by the CDI of selection, classification and evaluation that activate contexts of sociocultural knowledge of language speakers. Consider the metaconcept ROLES in the next sample (18):

(18) In the aftermath of T. J. Oshie's "heroic" shootout performance for the United States against the Russians this morning in Sochi, I put together this quick montage of Oshie's brilliance in the shootout (https://vk.com/video-40518256_168287676?list=4 $8 c d b e 97 d 3 f 825 f 7 d 0$ ).

The ROLE of the speaker is that of a spectator who constructs discourse within the conceptual-andthematic domain THEATRE by activating 'patriotic' meaning of the discourse via selection, classification and evaluation of particular semantic values that are represented by the lexical concepts [HEROIC], [PERFORMANCE], [BRILLIANCE]: heroic - "showing the qualities of a hero; extremely courageous (Gadsby, 1998, p. 622); performance - "the action or an act of performing a character in play, a piece of music, tricks (Gadsby, 1998, p. 1000); brilliance - "great skill or intelligence" (Gadsby, 1998, p. 336).

In the next sample (19), the ROLE of the language speaker is that of a correspondent who activates the context of professional knowledge about Mass Media Speech Etiquette:

(19) T.J. Oshie scored four times in the shootout and got the winner in the eight round, leading the United States past Russia 302 Saturday in the thrilling revival of an Olympic hockey rivalry (Costa, 2014).

In (19) the context of professional knowledge is represented by the lexical concepts [SCORE], [WIN], [LEAD], [RIVALRY] within the conceptual-andthematic domain COMPETITIVE GAMES. The CDI includes: i) selection of the lexical concepts [SCORE], [WIN], [LEAD] providing access to the context of knowledge related to 'the facts that are relevant for the reader'; ii) categorizing the event in terms of a very exciting sporting event by virtue of the lexical concept [THRILLING]; iii) referring to a feeling of deep emotion (evaluation). 
The metaconcept STEREOTYPES as a mental structure that generates qualities assigned to groups of people related to the nationality, gender roles, race, etc. reflects a person's sets of expectations about a social group's characteristics. Consider the next sample (20):

(20) HIGGINS. Pickering: this chap has a certain natural gift of rhetoric. Observe the rhythm of his native woodnotes wild. "I'm willing to tell you: I'm wanting to tell you: I'm waiting to tell you." Sentimental rhetoric! That's the Welsh strain in him. It also accounts for his mendacity and dishonesty (Shaw, 1994, p. 45).

In (20) the speaker of English activates his beliefs grounded on his experience with representatives of other cultural backgrounds. The CDI includes: i) selection of the lexical concepts [SENTIMENTAL], [WELSH], [MENDACITY], [DISHONESTY] providing access to the context of knowledge about ethnical identities; ii) categorizing the event in terms of negative generalizations by virtue of the lexical concept [WELSH]; iii) disapproval of the participant's (the chap's) behavior (evaluation).

The metaconcept VALUES provides guidelines for the speakers' behavior and sets of expectations, as in the next sample (21):

(21) 'Mr Stevens, I thought these would brighten your parlour a little.'

'I beg your pardon, Miss Kenton?'

'It seemed such a pity your room should be so dark and cold, Mr Stevens, when it is such bright sunshine outside. I thought these [flowers] would enliven things a little.'

'That's very kind of you, Miss Kenton'.

'It is a shame more sun doesn't get in here. The walls are even a little damp, are they not, Mr Stevens?'

$<\ldots>$

'If you wish, $\mathrm{Mr}$ Stevens, I might bring in some more cuttings for you'.

'Miss Kenton, I appreciate your kindness. But this is not a room of entertainment. I am happy to have distractions kept to a minimum' (Ishiguro, 1989, p. 68).
$\mathrm{Mr}$ Stevens constructs discourse within the conceptual-and-thematic domain TASK-FOCUSED ACTIVITY. Miss Kenton interprets the situation within the conceptual-and-thematic domain ENVIRONMENT-FOCUSED ACTIVITY. The CDI in (21) encompasses: i) selection of the lexical concepts [BRIGHTEN], [ENLIVEN] (Miss Kenton), [NO ENTERTAINMENT], [DISTRACTION] (Mr. Stevens); ii) categorizing the event in terms of making one's life better and bright (Miss Kenton) and negative judgments (Mr. Stevens) by virtue of the lexical concept [NOT A ROOM OF ENTERTAINMENT]; iii) offering some help (Miss Kenton) and disapproving of Miss Kenton's behavior (Mr. Stevens) (evaluation).

The metaconcept NORMS sets rules or standards of behavior that can be incorporated within the individual, or may be enforced from without:

(22) LIZA. Oh, don't be silly.

MRS. PEARCE. You mustn't speak to the gentleman like that.

LIZA. Well, why won't he speak sensible to me? (Shaw, 1994, p. 57).

Mrs. Pearce activates the context of knowledge of asymmetrical relationships (gentleman - not a lady) within the conceptual-and-thematic domain COMMUNICATION. The violation of norms of politeness as a context of knowledge of symmetrical communicative strategies marks Liza's discourse (human being - to human being). The CDI in (22) encompasses: i) selection of the lexical concepts [DO NOT BE SILLY], [SPEAK SENSIBLE] (Liza); [MUST NOT SPEAK], [GENTLEMAN] (Mrs. Pearce); ii) categorizing the event in terms of inappropriate behavior; iii) expressing dissatisfaction (evaluation).

The metaconcepts SPACE and TIME regulate special and temporal experience participants posses about the environment they live in:

(23) Kanyenda to help Sochi 2014 bid. Sochis Olympic officials, who are attending a sports seminar in the Malawian capital Blantyre this week, said on their Web site that they had chosen the 24-year-old FC Rostov 
striker for his worldwide appeal, especially in Africa. The striker briefly played for Lokomotiv Moscow in 2005 before returning to Rostov in the off season. He joins several of Russia's former Olympic Champions $<\ldots>$ as Sochis ambassadors (news.bbc.co.uk).

In (23) the context of knowledge of the bidding process for the Games that took part in the past is activated via past verb forms. The inference 'Sochi as the host city for Winter Olympics 2014 is not necessarily successful' is made by virtue of the CDI that encompasses such lexical concepts, as [BRIEFLY], [PLAYED OFF SEASON], [FORMER OLYMPIC CHAMPIONS], [KANYENDA TO HELP SOCHI] providing access to it.

Consider the next sample (24):

(24) Teenage golf star Michelle Wie is to become an honorary ambassador for the 2014 Winter Olympics bid of South Korean ski resort Pyeongchang. The 17-year-old, who has finished third in two majors, grew up in Hawaii but has Korean parents. "I'm proud of my Korean heritage and also a big fan of winter sports", said the American. "If the 2014 Winter Games are held in Pyeongchang I'm sure they will be a fantastic and memorable experience (news.bbc.co.uk).

In (24) the inference 'Pyeongchang as the host city for Winter Olympics 2014 is likely to be successful' is made by virtue of the CDI that encompasses the lexical concepts [BECOME AN HONONARY AMBASSADOR], [PROUD], [AMERICAN], [FANTASTIC], [MEMORABLE] providing access to the knowledge of low-context cultures typical patterns of behavior (be self-reliant, be focused on practical outcomes). The space - time reference is activated by the lexical and grammatical concepts [HAS FINISHED THIRD], [IF the 2014 WINTER GAMES ARE HELD].

The metaconcept LANGUAGE PERFORMANCE reflects the knowledge of language as a system to communicate in terms of language use in concrete situations as well as the 'intuitive feeling for language' that predisposes new words and creativity (for example, affluenza, Applepick, buzzword, etc.). Consider the next sample (25):

(25) MRS. EYNSFORD HILL [to Mrs. Higgins]. How do you do? [They shake hands].

MISS EYNSFORD HILL. How d'you do? [She shakes]. MRS. HIGGINS [introducing]. My son Henry.

MRS. EYNSFORD HILL. Your celebrated son! I have so longed to meet you, Professor Higgins. (Shaw, 1994, p. 78).

In (25) the context of knowledge about how to officially greet people is activated. Though, greeting exchange may take a number of forms including:

- a comment on the weather: Extremely hot, isn't it?

- a comment regarding length of time between contact: Haven't seen you for a long time.

- a question relating to activities: What have you been up to?

To compare, in the next sample (26), the language of medicine offering intriguing challenges to nonprofessionals is used:

(26) Thoracentesis is puncture through the chest wall for the purpose of aspiring pleural fluid. It is used to determine the etiology of a pleural effusion (diagnostic thoracentesis), to relieve dyspnea caused by pleural fluid (therapeutic thoracentesis), and, occasionally, to carry out pleurodesis $<\ldots>$ Ultrasonography, CT, or both may be useful if chest $x$-rays are equivocal, if prior thoracentesis attempts are unsuccessful, or if the fluid is loculated (Lechtzin, 2013).

\section{Conclusions and Future Study}

Sociocultural Commitment of Cognitive Linguistics provides an account of language which is cognitive and social. Sociocultural Commitment of Cognitive Linguistics can be revealed via context dimensions. Statically, contexts represent conceptual- 
and-thematic domains as cognitive models encoded by language. Dynamically, they profile meanings participants make as the result of the interpretive process of selection, classification and evaluation that constitute the cognitive-discursive interpretant. Collective vs. individual dimension presents encyclopaedic and sociocultural knowledge of language speakers. The metaconceptual structure of contexts encompasses ROLES, STEREOTYPES, VALUES, NORMS, SPACE, TIME, LANGUAGE PERFORMANCE as metaconcepts that establish language use and discourse construction. The Sociocultural Commitment of Cognitive Linguistics will stimulate future work in the field of Intercultural Communication.

Acknowledgements: This work is supported by research grant 15-18-10006 "A cognitive study of anthropocentric nature of language" of the Russian Science Foundation at Tambov State University named after G.R. Derzhavin.

\section{References}

Boldyrev, N. N. (2012). K voprosu ob integrativnoy teorii reprezentatsii znaniy $\mathrm{v}$ yazyike. Kognitivnyie issledovaniya yazyika, XII: Teoreticheskie aspektyi yazyikovoy reprezentatsii. Moskva: Institut yazyikoznaniya RAN; Tambov: Izdatelskiy dom TGU im. G.R. Derzhavina, 33-43.

. (2011). O metayazyike kognitivnoy lingvistiki: kontsept kak edinitsa znaniya. Kognitivnyie issledovaniya yazyika, IX: Vzaimodeystvie kognitivnyih i yazyikovyih struktur. Moskva: Institut yazyikoznaniya RAN; Tambov: Izdatelskiy dom TGU im. G.R. Derzhavina, 23-32.

(2013). Interpretatsionnyiy potentsial kontseptualnoy metaforyi. Kognitivnyie issledovaniya yazyika, XV: Mehanizmyi yazyikovoy kognitsii: sbornik nauchnyih trudov. Moskva: Institut yazyikoznaniya RAN; Tambov: Izdatelskiy dom TGU im. G.R. Derzhavina, 12-22.

(2014). Kontseptualno-tematicheskie oblasti yazyikovoy kartinyi mira i ih interpretiruyuschaya funktsiya. Kognitivnyie issledovaniya yazyika, XVII: Aktualnyie problemyi vzaimodeystviya myislitelnyih $i$ yazyikovyih struktur: sbornik nauchnyih trudov. Moskva: Institut yazyikoznaniya RAN; Tambov: Izdatelskiy dom TGU im. G.R. Derzhavina, 33-39.

Boldyrev, N.N., \& Dubrovskaya, O.G. (2015). Context of Sociocultural Knowledge in Discourse Construction. Mediterranean Journal of Social Sciences, 6 (1), S2, 2530. Retrieved from http://www.mcser.org
Costa, B. (2014). T.J. Oshie leads U.S. to epic Olympic hockey shootout win over Russia. Retrieved from http:// www.wsj.com

Dabrowska, E. \& Divjak, D. (2015). (Ed.). Introduction. Handbook of cognitive linguistics, 39, 1-9.

Demyankov, V.Z. (2005). Kognitsiya i ponimanie teksta. Voprosyi kognitivnoy lingvistiki, 3, 5-10.

Dilley, R. (1999). The Problem of context. New York; Oxford: Berghahn Books, 1999.

Evans, V. (2012). Cognitive linguistics. WIREs Cogn Sci 2012. Doi: $10.1002 /$ wcs. 1163 .

Findlater, C. (2007). (Ed.). Scottish Jokes. Waverley: Books Ltd.

Gadsby, A (Ed.). (1998). Longman dictionary of English language and culture. Edinburgh: Longman.

Hall, E.T. (1976). Beyond culture. Canada: Random House.

Halliday, M.A.K. (2003). On language and linguistics. London; New York: Continuum.

Ishiguro, K (1989). Remains of the day. Vintage Publishing.

Kolshanskiy, G.V. (2005). Kontekstnaya semantica. Moskva: KomKniga.

Kubryakova, E.S. (2004). Yazyik $i$ znanie: na puti polucheniya znaniy o yazyike. Chasti rechi s kognitivnoy tochki zreniya. Rol yazyika $v$ poznanii mira. Moskva: Yazyiki slavyanskoy kulturyi.

Lakoff, G. (1990). The invariance hypothesis. Is abstract reason based on image-schemas? Cognitive Linguistics, $1,39-74$.

Langacker R.W. (1987). Foundations of cognitive grammar. Theoretical prerequisites. Stanford: Stanford University Press.

Langacker, R.W. (2000). Grammar and conceptualization. Berlin; New York: Mouton De Gruyter.

Lechtzin, N (2013). Thoracentesis. Retrieved from http:// www.merckmanuals.com

Malinowski, B. (1989). A diary in the strict sense of the term. Stanford: Stanford University Press.

Shaw, G.B. (1994). Pygmalion. Dover Publications.

van Dijk, T. A. (2009). Society and discourse: how social contexts influence text and talk. Cambridge: Cambridge University Press.

Yule, G. (1997). Pragmatics. Oxford: Oxford University Press.

Recebido em: 14/09/2015 Aceito em: 24/11/2015 